\section{Kidney \\ Blood Pressure Research}

\title{
The Level of Anxiety and Depression in Dialysis Patients Undertaking Regular Physical Exercise Training - a Preliminary Study
}

\author{
Wioletta Dziubek ${ }^{a} \quad J o a n n a$ Kowalska ${ }^{a}$ Mariusz Kusztal ${ }^{b} \quad$ Łukasz Rogowskic $^{c}$ \\ Tomasz Gołębiowski ${ }^{b}$ Małgorzata Nikifura Joanna Szczepańska-Gierachaa \\ Agnieszka Zembroń-Łacny ${ }^{d}$ Marian Klinger ${ }^{b} \quad$ Marek Woźniewski ${ }^{a}$
}

aDepartment of Physiotherapy, University School of Physical Education, bepartment and Clinic of Nephrology and Transplantation Medicine, Wroclaw Medical University, ' Non-Public Medical College of Wroclaw, Wroclaw, dDepartment of Physical Education, University of Zielona Gora, Poland

\section{Key Words}

Anxiety $\cdot$ BDI $•$ Chronic kidney disease $\cdot$ Depression $•$ Regular physical exercise $\cdot$ STAI

\begin{abstract}
Background/Aims: The aim of the study was to evaluate the effects of a six-month physical training undertaken by haemodialysis (HD) patients, on the depression and anxiety. Methods: Patients with end stage renal disease (ESRD) were recruited from the dialysis station at the Department of Nephrology and Transplantation Medicine in Wroclaw. Physical training took place at the beginning of the first 4-hours of dialysis, three times a week for six months. A personal questionnaire, Beck Depression Inventory (BDI) and State-Trait Anxiety Inventory (STAI) were used in the study. Results: A total of 28 patients completed the study: 20 were randomised to endurance training and 8 were randomised to resistance training. Statistical analysis of depression and anxiety at the initial $\left(\mathrm{t}_{1}\right)$ and final examination $\left(\mathrm{t}_{2}\right)$ indicated a significant reduction in depression and anxiety, particularly anxiety as a trait (X2) in the whole study group. The change in anxiety as a state correlated with the disease duration, duration of dialysis and the initial level of anxiety as a state $\left(t_{1} \times 1\right)$. The change in anxiety as a trait significantly correlated with age and the initial level of anxiety $\left(t_{1} \times 2\right)$. Conclusions: Undertaking physical training during dialysis by patients with ESRD is beneficial in reducing their levels of anxiety and depression. Both resistance and endurance training improves mood, but only endurance training additionally results in anxiety reduction.
\end{abstract}




\section{Kidney Blood Pressure Research}

\section{Introduction}

The most common mental health problems of patients undergoing hemodialysis (HD), suffering from end-stage renal disease (ESRD), are depressive disorders. Their incidence is much higher than in other chronic conditions such as diabetes or congestive heart failure (CHF) [1, 2] ranging from $19 \%$ to $60 \%[3,4]$. Additionally, the authors report that $12 \%$ to $52 \%$ of hemodialysis patients experience anxiety during dialysis [3, 5]. Depressive disorders that occur as a result of complications of chronic kidney disease, and the anxiety that accompanies them, lower the quality of life of patients, but also according to studies increase their mortality [6-9].

Hemodialysis requires the patient to adapt to certain restrictions, such as the control of diet, fluid intake, chronic pain and discomfort associated with puncturing the arteriovenous fistula on the day of dialysis. Other somatic ailments are also involved often with numerous accompanying disorders, frequent hospital stays, as well as more frequent injuries during the patient's weakened state after dialysis. Also, problems in daily functioning, and fear of the future undoubtedly influence the onset of symptoms of depression and anxiety [3, 10, 11]. The source of the patient's anxiety are also invasive procedures accompanying hemodialysis such as: inserting a needle into the arteriovenous fistula, implanted central venous catheters, alarm sounds going off in the dialysis machine and renal staff changing shift at the dialysis station (e.g. a lack of a permanent nurse who punctures the fistula "properly") [12].

Long-term dialysis interferes and leads to an unfavourable self-image, causing many negative emotions such as despondency, anger, dissatisfaction and disappointment [13]. A source of anxiety for the patients undergoing long-term hemodialysis is undoubtedly their current health status and awareness of reduced control over their own health. End-stage renal failure leads to multiple, sudden, unexpected and often serious health crises. In the USA withdrawal from dialysis along with suicide is the third most common cause of death in dialysis patients. In addition, patients experience anxieties about their well-being after each dialysis. Patients cannot predict how they are going to respond to treatment, which evokes a sense of helplessness [14].

Commencing dialysis significantly changes the patients' relationships with the immediate environment, their ability to perform social roles both in the family and in society at large. The need to give up their jobs with the ensuing financial troubles, submit to fixed days and hours of treatments, repeated hospitalizations and awareness of their growing dependence on other people, additionally lowers their self-esteem. The chronic and long-term illness and its complications forces readjustment of the whole life, while it can also lead to a loss of meaning of life and an emergence of worsening depressive symptoms [13].

On the other hand, patients who express willingness to be the recipient of a transplant are exposed to constant anxiety due to the fact that their health needs to be good enough to be put on a waiting list for a transplant. Patients also experience anxiety around the probability of obtaining a kidney transplant.

Therefore, undertaking physical activity in patients with end-stage renal disease seems justified. Physical exercise in dialysis patients leads to further enhancement and effectiveness of the treatment performed. Furthermore, it has a favourable effect on the increase in volume and ejection fraction of the heart, and on reduction in stiffness and resistance of blood vessels as well as on reduction in total and LDL cholesterol values. As a result, this is conducive to blood pressure normalization $[15,16]$.

Undertaking regular physical activity significantly affects the microscopic and metabolic changes in skeletal muscles. The increase in quantity of muscle fibres, in particular type II A, increased activation of satellite cells, increased number of mitochondria and blood vessels have been proven [15-18].

In the case of depressive and anxiety disorders, a mechanism based on psychological ("self-confidence" and the concept of distractors) and biological theory (i.a. $\beta$-endorphine and thermogenic theories) seems particularly important $[19,20]$. 


\section{Kidney \\ Blood Pressure Research}

Kidney Blood Press Res 2016;41:86-98

DOI: $10.1159 / 000368548$

Published online: February 15, 2016

Dziubek et al.: The Anxiety and Depression in Dialysis Patients

Among the non-pharmacological methods to potentially reduce anxiety-depressive symptoms, behavioural therapy, occupational therapy, music therapy and physical exercise are mentioned. In addition, physical activity and exercise can reduce fatigue levels, one of the major factors contributing to the low QoL of HD patients [21, 22].

The impact of two different exercise modalities -endurance and resistance - on the depression/anxiety symptoms may differ due to the divers functional effects. Endurance training, referring to aerobic exercises (for example running), improves functional capacity better than resistance training as it has a positive influence on the cardiovascular system - improves blood flow and oxygen uptake. The resistance training improves muscle strength (muscular endurance) - it refers to weight lifting or anything that requires you to move an object [22].

The data on the effectiveness of physical training are very scarce which prompted the research below. The aim of the study was to evaluate the effects of a six-month regular physical exercise programme undertaken by dialysis patients on the symptoms of depression and anxiety. The secondary aim was a comparison of the effects of the two different types of training types.

\section{Materials and Methods}

\section{Participants}

The research was conducted at the dialysis center of the Department of Nephrology and Transplantation Medicine at the Medical University in Wroclaw. The study group included patients who met the following inclusion criteria: end-stage renal failure, hemodialysis therapy for at least 6 months prior to the start of research, patient's informed consent to participate in the study and lack of medical contraindications to exercise training confirmed by physician. With respect to the use of questionnaires assessing the symptoms, as basic research tools, the final analysis excluded (censored data) patients who died during the study, received a kidney transplant, did not want to complete the questionnaire again or attended less than 50 training sessions. A minimum $69 \%$ compliance rate (i.e. 50 completed sessions) was set in line with previous recommendations in this population [23]. Lack of cooperation (mainly due to dementia) and lack of informed written consent were other reasons for exclusion from the study.

To participate in the study, patients were qualified by a nephrologist and cardiologist. The nephrologist's permission to participate in the study was based on the patient's present condition and biochemical results. The condition/comorbidities which did not allow patients to participate were as follows: poorly controlled hypertension, severe symptomatic arrhythmia (causing hypotonia), acute coronary syndrome in the last 4 weeks, unstable angina, heart failure ( $>$ II in NYHA grading), hyperkaliemia ( $>6 \mathrm{mmol} / \mathrm{l})$, hypokaliemia $(<3,5 \mathrm{mmol} / \mathrm{l})$, severe anemia $(\mathrm{Ht}<25 \%)$, uncontrolled renal osteodystrophy or osteoporosis confirmed by DEXA, musculoskeletal deformation, acute illness (recent fever, pain/fever of unknown origin).

Each patient was informed of the voluntary nature of participation in the study and of the option to withdraw during the exercise training. The study was approved by the local bioethics committee and conforms to Helsinki Declaration. A total of 37 patients met the study criteria and underwent cluster randomisation (Fig 1).

\section{Study design}

A cluster randomised uncontrolled trial methodology was employed [24, 25]. A cluster (group/place) in the study was formed by group of subjects attending to dialysis sessions regularly performed in the same room (one of two available room) at one of six available dialysis shifts. We followed the rule that one type of training was provided for one cluster (patients in one room for dialysis shift).

The patients were divided into two groups:

- group I - subjects, for whom endurance training was adopted (21 persons),

- group II - subjects, for whom resistance training was adopted (16 persons).

During the research, these groups were reduced due to: kidney transplantation (3 persons), death (4 persons), lack of patient consent to fill out the questionnaires again (1 person), and insufficient participation in the exercise training (1 person). 
Fig. 1. The recruitment process towards the study group.

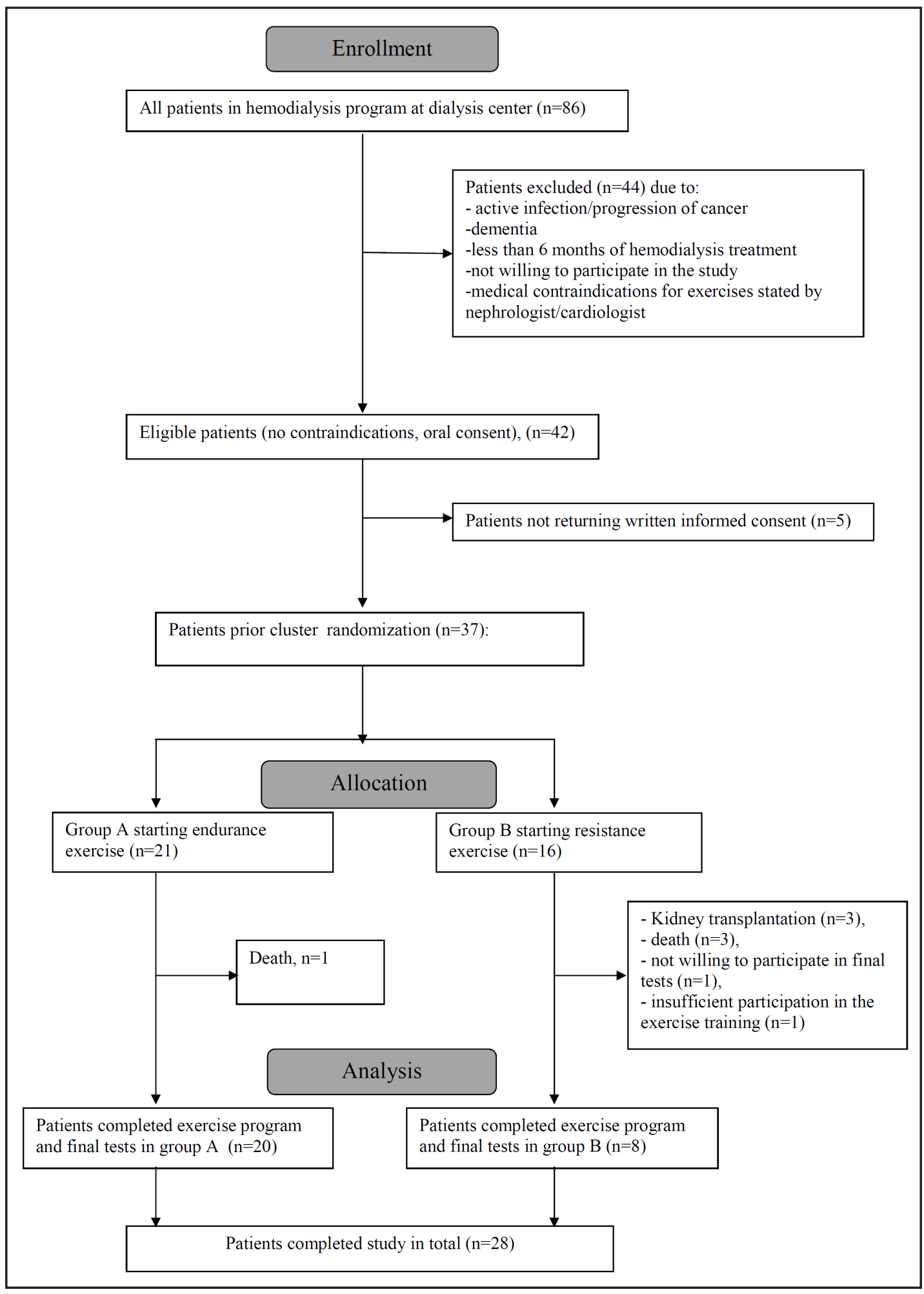

At the dialysis center there are 21 numbered dialysis chairs allocated in two rooms $(15+6)$. The explanation of non equal arms in the study ( 21 vs 16 ) is related to diverse number of patients willing to participate in the study on each shift. The rule that one type of training was provided for one cluster was followed. 


\section{Kidney \\ Blood Pressure Research}

Kidney Blood Press Res 2016;41:86-98

\begin{tabular}{l|l}
\hline DOI: $10.1159 / 000368548$ & (C) 2016 S. Karger AG, Basel
\end{tabular}

Published online: February 15, 2016

www.karger.com/kbr

Outcome Measures

The following tools were used in the study:

- a personal questionnaire,

- the Beck Depression Inventory (BDI),

- $\quad$ Spielberg's State-Trait Anxiety Inventory (STAI).

Each patient filled in a personal questionnaire once at the start of the training, and the BDI and STAI twice, at the start of the training $\left(\mathrm{t}_{1}\right)$ and after 6 months $\left(\mathrm{t}_{2}\right)$.

A personal questionnaire

The questionnaire consisted of two parts and included both sociodemographic data (age, gender, marital status, number of children, education and clinical data (related to the disease: date of diagnosis, dialysis vintage, the cause of insufficiency, the number of medications and comorbidities). The questionnaire was self-administered, however, an assistant was available to answer any questions or explain how to fill in the form. The first part was to be filled in by the patient, the other part by staff, based on medical history report. Also, staff verified the sociodemographic data given by the patient. All anthropometric measurements were taken directly on site (e.g. height, weight).

Beck Depression Inventory (BDI)

To assess the severity of depressive symptoms BDI was used [26]. The BDI is considered an accurate and reliable tool for assessing depressive symptoms. The scale contains 21 questions that relate to the most significant symptoms of depression. The first 13 questions concern the cognitive-affective area, other questions concern the somatic problems accompanying mood disorders. Higher total scores indicate more severe depressive symptoms [27].

State-Trait Anxiety Inventory (STAI)

STAI was used to assess the level of anxiety as a state and as a trait. The subscale of anxiety as a state (X1) is used to study the current mood of the respondent. Trait anxiety subscale (X2) illustrates how the assessed person usually feels. Measurement does not include somatic manifestations of anxiety. The criterion for dividing patients into subgroups of low and high level of anxiety for the STAI (X1) was a score of 44, and for STAI (X2) a score of 46. The summed up results for each of the two parts of the questionnaire range from 20 points - mild anxiety, to 80 points - very strong anxiety $[28,29]$.

\section{Physical Exercise Training}

Trainings were conducted three times a week for a period of 6 months. They took place in the first 2 hours of hemodialysis on the seat the patient used for dialysis. Trainings were constantly supervised by a nephrologist and a physiotherapist. Each training was divided into three parts:

1) Introductory part, a short warm-up lasting 5 minutes. It included active exercises of the lower limbs in recumbent position.

2) Main part, 10-15 min. In this part, depending on the training allocated:

Group 1 performed endurance training on a MOTOmed letto2cycle ergometer (RECK, Germany) which is a motorized exercise therapy device that has a CE 0124, EMV, ISO Qualitätsmanagement safety certificate which enables a patient to ride in a recumbent or reclined position. Training on ergometer concentrates on lower limbs, the position was chosen by the patient according to their comfort and, just as important, to the fluency of dialysis.

Training intensity was selected on the basis of subjective feelings of the patient and steadily increased from low to moderate levels based on a 10-point fatigue assessment (Borg scale). This is a reliable indicator for evaluating the intensity of physical exercise, among dialysis patients. In the first week of training the length of the cycle ergometer ride was 10 minutes. The objective was to reach exercise intensity level 3 according to the RPE scale. The time was steadily increased while maintaining a moderate level of intensity for a minimum of 2 to 3 weeks. The final stage of rehabilitation was the accomplishment of a 35-50-minute ride on the cycle ergometer at a moderate level of intensity [30]. The exercise was carried out until reaching subjective feeling of fatigue (5-6 on the 10 -point Borg scale)

The number of evolutions and load were constant, individually tailored to the patient depending on the tolerance of a given exercise. They were as follows: speed regulation from 10 to 60 [RPM], regulation of 


\section{Kidney \\ Blood Pressure Research}

Kidney Blood Press Res 2016;41:86-98

\begin{tabular}{l|l}
\hline DOI: $10.1159 / 000368548$ & (C) 2016 S. Karger AG, Basel
\end{tabular}

Published online: February 15, 2016

www.karger.com/kbr

Dziubek et al.: The Anxiety and Depression in Dialysis Patients

motor power from 1 to 10 [Nm], and preset therapy duration from 0 to 120 minutes. The parameters were selected in such way that the number of revolutions and the workload made it an endurance type of training. It should be added that the course of training shown on the ergometer screen in the form of a power level achieved [W] for both lower limbs was a motivating factor for the patient to continue with the exercise.

Group 3 performed strength (resistance) exercises with weights, balls and Thera Bands. Mostly the lower limbs and one upper limb free of the arteriovenous fistula were engaged.

Exercises of the lower limbs included: straightening / bending of the knee, straightening / bending at the hip, adduction / abduction at the hip.

Exercises of the upper limbs included: "rowing" single-handedly (limb adduction to the body in the sagittal plane); "squeezing" with one hand (bending limbs in the shoulder joint in the transverse plane, limb in $90^{\circ}$ abduction in the coronal plane), bending the forearm at the elbow joint; straightening the forearm in the elbow joint).

One exercise in each exercise referral scheme was performed, the workout consisted of 4 - 5 sets; 1 lightweight 20 repetitions, 2-5 main of 10 - 20 reps; until exhaustion. The intensity was determined according to subjective feelings, matching color-coded bands or weights adequately. The intensity was increased by raising the number of sets or repetitions while maintaining the load. In the case when a patient reported tolerance, training load was increased and maintained at a constant level for at least 3 trainings ( 1 week) in order to adapt to a new load. If the patient showed some progress, the load was increased also in the following week. Only in the case of indisposition was the load reduced, however, at the next training the previous load was restored. Exercise was performed until onset of subjective feelings of exhaustion (at the beginning 5-6 in the 10-point Borg scale), however, not until "muscle failure" (in order to avoid the risk of injuries in and around tendons, muscle attachments, etc.).

Weights used for the lower limbs were: $1.1 \mathrm{~kg}-3.7 \mathrm{~kg}$; for upper limbs: $1-3 \mathrm{~kg}$. The duration of the main part was increased gradually from 10 minutes in the initial period of training up to 50 minutes. Resistance training was completed in a seated position.

3) Final part, relaxation, lasted about 5min. and included free active exercises of the lower limbs in recumbent position as well as breathing exercises.

Stopping exercises during the training session was allowed in cases where a participant was feeling unwell or fatigued, experienced the onset of muscular, joint or coronary pain, nausea, dizziness or shortness of breath, obtained a heart rate above $80 \%$ of maximum (HRmax), exceeded blood pressure values above $200 / 110 \mathrm{mmHg}$ or below $110 / 50 \mathrm{mmHg}$, and in the case of incapacity to maintain the recommended exercise pace. For safety reasons, heart rate, blood pressure and the degree of subjective fatigue levels according to the 10-point Borg scale were monitored before, during and after exercise.

\section{Statistical analysis}

Statistical analysis was conducted using STATISTICA 10 software by StatSoft, Poland. A statistical description of the material was given as mean values, medians and standard deviations while the variation range was determined by specifying the minimum and maximum value in the distribution of characteristics. The normality of empirical distribution was verified using the Shapiro-Wilk's test. Due to the nature of the data non-parametric tests were used in the analysis: Mann-Whitney test (gender differences and the effects of both the endurance and resistance trainings were examined) and Wilcoxon's test (BDI and STAI changes). The interdependence of categorized characteristics was tested using Pearson's chi-square independence test $(\chi 2)$. To examine the relationships between variables Spearman's rank correlation coefficient rho was determined. The limit of significance was set at $<0.05$.

\section{Results}

At the end of the research project a total of 28 patients remained. Their mean age was $63.4 \pm 13.7$, including 14 women and 14 men: 20 patients participating in endurance training (71\% of the group) and 8 persons participating in resistance training (29\% of the group). The characteristics of the study group are shown in Table 1.

The initial examination of the level of anxiety and depression showed that out of 28 respondents, as many as $67.9 \%$ have symptoms of depression in at least mild form, 50\% 


\section{Kidney Bloód Pressure Research}

have elevated anxiety as a state (X1), and in $28.6 \%$ of patients there is an increased level of anxiety as a trait (X2). In the entire study group women had slightly lower levels of depression and tended to have higher levels of anxiety, especially anxiety as a state (not statistically significant).

T a b l e 2 displays a comparison of the average values and medians of the distribution of depression and anxiety at initial $\left(\mathrm{t}_{1}\right)$ and final exa m ination $\left(t_{2}\right)$ in the whole study group. After a six-month physical exercise training, an improvement to mental well-being occurred in the majority of respondents but only improvement in mood was statistically significant $\left(t_{1}\right.$ BDI vs. $t_{2} B-$ DI, $p=0.012$ ).

\begin{tabular}{|c|c|c|c|}
\hline Baseline characteristics & $\begin{array}{c}\text { Total } \\
\text { Patients } \\
(\%) \\
(\mathrm{n}=28)\end{array}$ & $\begin{array}{c}\text { Resistance } \\
\text { training } \\
\text { group } \\
(\mathrm{n}=8)\end{array}$ & $\begin{array}{c}\text { Endurance } \\
\text { training } \\
\text { group } \\
(\mathrm{n}=20)\end{array}$ \\
\hline \multicolumn{4}{|l|}{ Age } \\
\hline Mean (SD) & $63.4(13.7)$ & $56.4(13.6)$ & $66.3(13.1)$ \\
\hline Range & $29-84$ & $38-77$ & 29-84 \\
\hline \multicolumn{4}{|l|}{ Gender } \\
\hline Women & $14(50)$ & $3(37.5)$ & $11(55)$ \\
\hline Men & $14(50)$ & $5(62.5)$ & $9(45)$ \\
\hline \multicolumn{4}{|l|}{ Education } \\
\hline Primary and vocational & $7(25)$ & $2(25)$ & $5(25)$ \\
\hline Secondary & $13(46)$ & $1(12.5)$ & $12(60)$ \\
\hline Higher & $8(29)$ & $5(62.5)$ & $3(15)$ \\
\hline \multicolumn{4}{|l|}{ Marital status } \\
\hline Married & $20(71)$ & $7(87.5)$ & $13(65)$ \\
\hline Single people (widow(er), unmarried) & $8(29)$ & $1(12.5)$ & $7(35)$ \\
\hline \multicolumn{4}{|l|}{ Cause of ESRD } \\
\hline Unknown & $3(11)$ & 0 & $3(15)$ \\
\hline Nephropathy (diabetic + hypertensive) & $11(39)$ & $4(50)$ & $7(35)$ \\
\hline Glomerulonephritis, & $9(32)$ & $3(37.5)$ & $6(30)$ \\
\hline ADPDK & $3(11)$ & 0 & $3(15)$ \\
\hline Other & $2(7)$ & $1(12.5)$ & $1(5)$ \\
\hline \multicolumn{4}{|l|}{ Disease duration (years) } \\
\hline Mean (SD) & $13.5(10.2)$ & $9.0(6.8)$ & $15.2(10.9)$ \\
\hline \multicolumn{4}{|l|}{ Duration of dialysis (years) } \\
\hline Mean & $5.5(4.3)$ & $4.4(3.2)$ & $6.0(4.7)$ \\
\hline \multicolumn{4}{|l|}{ Number of medicines } \\
\hline Mean (SD) & $6.4(4.2)$ & $9.4(6.0)$ & $5.2(2.6)$ \\
\hline \multicolumn{4}{|l|}{ Number of comorbidities } \\
\hline Mean (SD) & $1.7(1.1)$ & $2.1(1.2)$ & 1.5(1.1) \\
\hline \multicolumn{4}{|l|}{ Co-morbidities } \\
\hline hypertension & 14 & 6 & 8 \\
\hline diabetes & 12 & 4 & 8 \\
\hline \multicolumn{4}{|l|}{ Cardiovascular disease (ischemic heart } \\
\hline disease, atrial fibrillation, TIA, stroke) & 9 & 2 & 7 \\
\hline peripherial artery disease & 2 & 0 & 2 \\
\hline degenerative joint disease & 2 & 1 & 1 \\
\hline other & 3 & 2 & 1 \\
\hline none & 4 & 0 & 4 \\
\hline
\end{tabular}

Table 2. The level of depression and anxiety at the start of training $\left(\mathrm{t}_{1}\right)$ and after 6 months $\left(\mathrm{t}_{2}\right)$ in the study group $(\mathrm{n}=$ 28).

\begin{tabular}{lccccc}
\hline \multirow{2}{*}{ Variables } & & & \multicolumn{3}{c}{ Wilcoxon Test } \\
\multirow{2}{*}{ BDI } & t1 & $15.5(9.3)$ & 12.5 & \multirow{2}{*}{0.50} & \multirow{2}{*}{0.012} \\
& t2 & $11.6(9.3)$ & 9.5 & & \\
\hline \multirow{2}{*}{ STAI X1 } & t1 & $39.3(11.8)$ & 39.0 & \multirow{2}{*}{0.30} & \multirow{2}{*}{0.761} \\
& t2 & $38.2(9.2)$ & 39.0 & & \\
\hline \multirow{2}{*}{ STAI X2 } & t1 & $41.7(9.6)$ & 40.5 & \multirow{2}{*}{1.66} & \multirow{2}{*}{0.096} \\
& t2 & $39.1(9.2)$ & 38.5 & & \\
\hline
\end{tabular}

STAI X1- State-Trait Anxiety Inventory, state anxiety subscale; STAI X2- State-trait Anxiety Inventory, trait anxiety subscale ; BDI - Beck Depression Inventory; t1 - first measuring point (before training); $\mathrm{t} 2$-second measuring point (after training) 


\section{Kidney Blood Pressure Research}

Table 3. The relation between changes to depression and anxiety and the type of training (the minus sign indicates a decrease)

\begin{tabular}{|c|c|c|c|c|c|c|c|}
\hline \multirow[t]{2}{*}{ Variables } & \multirow{2}{*}{$\begin{array}{l}\text { Type of } \\
\text { training }\end{array}$} & \multirow{2}{*}{$\begin{array}{c}\mathrm{t} 1 \\
\operatorname{Mean}(\mathrm{SD})\end{array}$} & \multirow{2}{*}{$\begin{array}{c}\mathrm{t} 2 \\
\text { Mean(SD) }\end{array}$} & \multicolumn{2}{|c|}{$\begin{array}{c}\text { Changes after } \\
\text { training }\end{array}$} & \multicolumn{2}{|c|}{$\begin{array}{c}\text { Mann- } \\
\text { Whitney Test }\end{array}$} \\
\hline & & & & Mean & Median & $\mathrm{Z}$ & $P$ \\
\hline \multirow{2}{*}{ BDI } & Kes & $14.0(8.1)$ & $11.0(6.3)$ & -3.0 & -2.0 & \multirow{2}{*}{0.38} & \multirow{2}{*}{0.702} \\
\hline & Endurance & $16.1(9.9)$ & $11.9(10.5)$ & -4.2 & -4.0 & & \\
\hline \multirow{2}{*}{ STAI X1 } & Resi & $37.5(5.6)$ & $41.9(5.0)$ & 4.4 & 4.5 & \multirow{2}{*}{2.22} & \multirow{2}{*}{0.027} \\
\hline & Endu & $40.0(13.6)$ & $36.8(10.2)$ & -3.2 & -2.0 & & \\
\hline \multirow{2}{*}{ STAI X2 } & Resistance & $41.3(5.9)$ & $41.4(9.7)$ & 0.1 & -0.5 & \multirow{2}{*}{0.97} & \multirow{2}{*}{0.332} \\
\hline & Endurance & $42.0(10.8)$ & $38.3(9.1)$ & -3.7 & -3.0 & & \\
\hline
\end{tabular}

STAI X1- State-Trait Anxiety Inventory, state anxiety subscale; STAI X2- State-trait Anxiety Inventory, trait anxiety subscale ; BDI - Beck Depression Inventory; t1 - first measuring point (before training); $\mathrm{t} 2$-second measuring point (after training)

Both resistance and endurance training did not affect improvement in the mood of patients on dialysis, the difference between groups was not statistically significant $(\mathrm{p}=0.702$; Table $3)$. On the other hand, interesting results were observed in the case of anxiety as a state (X1). Although, in the whole study group the difference between initial (T1) and final (T2) results was not statistically significant $(\mathrm{p}=$ 0.761, Table 2), depending on the type of training used, varying directions of changes in the experienced fear levels were reported. The resistance training resulted in an increase in anxiety as a state, in contrast, endurance training led to a reduction in anxiety as a state. The difference
Table 4. Spearman's correlation of variables in the study group $(n=28)$

\begin{tabular}{lcc}
\hline Changes BDI after training vs: & $\begin{array}{c}\text { rho- } \\
\text { Spearman }\end{array}$ & $\mathrm{p}$ \\
\hline age & 0.460 & 0.014 \\
disease duration & 0.113 & 0.567 \\
hemodialysis vintage & -0.042 & 0.832 \\
the number of training sessions & 0.356 & 0.063 \\
the number of comorbidities & 0.253 & 0.130 \\
t1BDI & 0.464 & 0.013 \\
\hline Changes STAI X1 after training vs: & & \\
\hline age & 0.115 & 0.559 \\
disease duration & 0.432 & 0.022 \\
hemodialysis vintage & 0.468 & 0.012 \\
the number of training sessions & 0.014 & 0.944 \\
the number of comorbidities & 0.316 & 0.056 \\
t1STAI X1 & 0.598 & 0.001 \\
\hline Changes STAI X2 after training vs: & & \\
\hline age & 0.398 & 0.031 \\
disease duration & 0.218 & 0.266 \\
hemodialysis vintage & 0.091 & 0.646 \\
the number of training sessions & 0.281 & 0.147 \\
the number of comorbidities & 0.345 & 0.036 \\
t1STAI X2 & 0.463 & 0.013 \\
\hline
\end{tabular}

between groups was statistically significant (Table 3). The results may suggest that the effectiveness of endurance training is greater than resistance training, however, the observed dependence on the type of training used was statistically significant only in respect of changes to the state anxiety (X1) (Table 3). These results definitely require further research and verification on a larger group of subjects.

Spearman's correlation was also determined in terms of changes in depression after exercise training with the age, disease duration, duration of dialysis, number of training sessions undertaken and mood levels at the start of the research ( $t_{1}$ BDI). Mood changes caused by regular exercise training were strongly and positively correlated with age and $t_{1}$ BDI, which means that greater mood improvement after exercise training was generally attained by elderly people and those with lower mood at the commencement of training, while the 


\section{Kidney Blood Pressure Research}

Kidney Blood Press Res 2016;41:86-98

\begin{tabular}{l|l}
\hline DOI: $10.1159 / 000368548$ & (C) 2016 S. Karger AG, Basel
\end{tabular}

Published online: February 15, 2016

www.karger.com/kbr

Dziubek et al.: The Anxiety and Depression in Dialysis Patients

number of training sessions undertaken correlated positively with the change in mood. This correlation was noticeable ( $p=0.063)$, but statistically not significant. Correlations with other characteristics were weak and not statistically significant (Table 4). There was also no significant association between gender, marital status or education of patients with the effects of six-month regular exercise programme.

The change in anxiety as a state after the six-month exercise programme significantly correlated with the disease duration, duration of dialysis and the initial level of anxiety as a state $\left(\mathrm{t}_{1} \mathrm{X} 1\right)$. On the other hand, the correlations of changes with age and the number of training sessions were insignificant. The respondents who showed a reduction in anxiety as a state after training sessions, were mainly patients who were suffering longer, who had been subjected to dialysis for longer periods of time, and who had higher levels of anxiety at the beginning of the study (Table 4). Also, the number of comorbidties might be important in larger population. Correlation analysis showed a result on the borderline of statistical significance, meaning that a greater reduction in anxiety as a state was achieved in patients burdened with fewer comorbidities (Table 4).

Single persons, widows and widowers experienced an increase in their anxiety as a state more frequently despite exercise training. The relation between marital status and changes to anxiety as a state after exercise training was statistically significant $(p=0.049)$. In contrast, no significant correlation was recorded for patients' gender and education with regards to changes in anxiety as a state.

The change in anxiety as a trait after a six-month exercise programme clearly and significantly correlated with age, the initial level of anxiety $\left(t_{1} X 2\right)$ and the number of comorbidities. The positivity of these correlations indicates that a reduction in anxiety as a trait after exercise training occurred primarily in the elderly and in people with fewer comorbidities and higher levels of anxiety at the beginning of the study. On the contrary, younger people and people with lower initial anxiety as a trait, attained only a slight reduction in anxiety as a trait, while some have even experienced a rise in anxiety (Table 4).

In the case of people with secondary and tertiary education, after a series of training sessions a reduction in anxiety as a trait occurred significantly more often than in subjects with vocational education. This association was statistically significant $(p=0.018)$. There was no significant relation between gender or marital status and the changes to anxiety as a trait in examined patients.

\section{Discussion}

Depression is the most commonly observed mental disorder among patients undergoing dialysis. This study revealed that nearly $68 \%$ of respondents had symptoms of depression. A similar high percentage (19\% to $60 \%)$ of prevalence of depression have been demonstrated in studies by Hmwe et al. [3] and Wang and Chen [4].

Apart from depression, patients also struggled with anxiety disorders. Elevated levels of anxiety were observed in approximately $50 \%$ of patients. This result is consistent with studies by Sapilak and Steciwko conducted on a group of 400 people undergoing hemodialysis, which showed that depression occurred in $60.4 \%$ of patients, whereas $53.3 \%$ of respondents showed symptoms of anxiety [31]. Knowing the mechanism of the effects of physical activity on the occurrence of depressive and anxiety disorders [32, 33], it seems important to develop the most effective training models that could improve the mental and functional state of dialysis patients [34]. Exercise training conducted during hemodialysis is considered by many authors as the most convenient way to increase physical activity and improve well-being of patients [35, 36].

The two types of six-month regular physical training (resistance and endurance) proposed in this study, correlated with a reduction in the symptoms of depression in the final examination and with a reduction in anxiety, mainly as a trait. Nevertheless, it is worth not- 


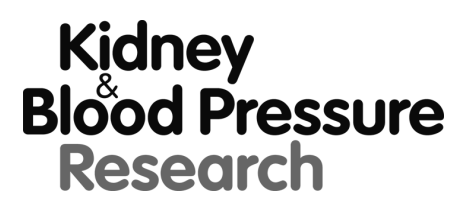

Kidney Blood Press Res 2016;41:86-98

\begin{tabular}{l|l}
\hline DOI: $10.1159 / 000368548$ & (c) 2016 S. Karger AG, Basel
\end{tabular}

Published online: February 15, 2016

www.karger.com $/ \mathrm{kbr}$

ing that the analysis of the results obtained indicates a greater effectiveness of endurance training, especially in the case of anxiety as a state. Therefore, it can be suggested that this form of training received the greatest acceptance by dialysis patients. Perhaps this is because of the form of physical exercise training itself, which was conducted in safe and comfortable positions for the patients and mainly used lower limbs, and did not require special concentration or any concern that it is being performed improperly. Penninx et al. have also made a comparison of the impact of 18-month training using resistance and endurance exercises on the level of depression. They showed that endurance training, which was based on walking, caused a significant reduction in symptoms of depression [37].

On the other hand, the resistance training performed in this study caused a slight increase in anxiety as a state, which in this case may have been associated with a greater movement in the exercises (also involving the upper limb that was free of the arteriovenous fistula), the necessity to correctly perform the exercises and fear of damage to the arteriovenous fistula or apparatus. These studies, however, require follow-up, particularly that this group was smaller.

In our research, the number of exercise sessions did have an impact on improving mood in patients on dialysis. Similarly, as in the studies by Gołębiowski et al. in patients who exercised regularly and did not miss many training sessions, a decrease in depression has been observed [16]. Anxiety did not improve under the influence of workouts. The explanation of this may be, that the group of patients with chronic renal failure is a group with a very advanced stage of the disease. Coming to the dialysis they are not able to predict their well-being or the body's response to the treatment on a given day. For this reason, they may experience nervousness and apprehension despite the physical exercise trainings undertaken. Also, the number of comorbidities affected the level of anxiety as a state and as a trait. In patients with more comorbidities changes in anxiety after training were smaller.

The biggest improvement in mood and reduction in anxiety as a trait was observed among older patients. Our observations showed, that younger people were less interested in the exercise classes, during hemodialysis and were less motivated to perform physical workouts. On the other hand older people willingly participated in the training sessions, although their health status was often significantly worse compared to younger patients. Further, Frazer et al. noticed that for older people with depression, regular physical exercise is among the most effective treatments [38] and is now considered a suitable alternative to antidepressants in this group. Although antidepressants may achieve a more rapid onset of therapeutic effect, physical activity has the added benefit of improving physical functioning [39].

Another factor in reducing anxiety as a trait was education. Greater awareness of the benefits that physical exercise brings and a conviction that making an effort in order to overcome difficulties makes sense, can cause a lasting change and better attitude to anxious situations. The biggest change in anxiety as a state after completing the exercise programme took place in patients who were sick and who had hemodialysis for longer period of time. Perhaps, it is in this group of patients that physical exercise better diverted their attention from the anxiety that accompanies them, despite being familiar with the procedures associated with dialysis.

We also observed a reduction in symptoms of depression and anxiety in persons with the lowest mood and high levels of anxiety upon commencement of exercise training. Perhaps, the high levels of depression and anxiety at the beginning of training can be understood, according to Simon, as helplessness in the face of chronic health problems and a difficult life situation, rather than a lack of motivation for therapy [40]. Perhaps the suggestion of non-pharmacological therapy training gave patients the motivation to improve their health, but most of all, gave patients a sense of being able to influence their own fate. 


\section{Kidney \\ Blood Pressure Research}

Kidney Blood Press Res 2016;41:86-98

\begin{tabular}{l|l}
\hline DOI: $10.1159 / 000368548$ & (C) 2016 S. Karger AG, Basel
\end{tabular}

Published online: February 15, 2016

www.karger.com/kbr

Dziubek et al.: The Anxiety and Depression in Dialysis Patients

\section{Limitations}

The described study has several limitations. It should be noted, that the studies carried out were of a screening nature and the findings obtained were not unequivocal with making a medical diagnosis. The study was not controlled for the primary aim (depression and anxiety). We used cluster randomisation method which is considered as random type of sampling with some drawbacks - does not give a precise picture of the whole population.

The high prevalence of depressive symptoms as indicated in the BDI tool may also influence different cut-off points when qualifying to mild or severe depressive symptoms in dialysis population. The studied groups were too small, especially the group undertaking resistance training; the results require confirmation using a larger group of patients as well as completing research results with further studies carried out using a control group.

\section{Conclusion}

The results obtained are promising and may suggest that performing regular physical activity during dialysis by patients with ESRD can reduce levels of anxiety, particularly symptoms of depression. Both resistance and endurance training improves mood, but only endurance training additionally results in anxiety reduction. The greatest improvement was observed in elderly patients and patients with higher levels of depression and anxiety at the beginning of the regular physical exercise programme.

\section{Disclosure Statement}

The authors of this work declare that they do not have any conflict of interests.

\section{Acknowledgments}

The authors thank the nursing and medical staff at the Dialysis Center at the University Hospital in Wroclaw for their friendly support.

This research presents grant results, from the National Science Centre Poland, no. 2011/03/B/NZ7/01764, titled "Effects of exercise training on muscle regenerative activity in hemodialysis patients". The funding agency had no role in the study design; collection, analysis, and interpretation of data; or the decision to submit this original work for publication.

\section{References}

1 Sanathan SR, Menon VB, Alla P, Madhuri S, Shetty MS, Ram D: Depressive symptoms in chronic kidney disease patients on maintenance hemodialysis. J Pharm Pharm Sci 2014;3:535-548.

2 Hedayati SS, Yalamanchili V, Finkelstein FO: A practical approach to the treatment of depression in patients with chronic kidney disease and end stage renal disease. Kidney Int 2011;81:247-255.

3 Hmwe NT, Subramanian P, Tan LP, Chong WK: The effects of acupressure on depression, anxiety and stress in patients with hemodialysis: A randomized controlled trial. Int J Nur Stud 2015;52:509-518.

4 Wang LJ, Chen ChK: The psychological impact of hemodialysis on patients with chronic renal failure; in: Polenakovic M (eds): Renal Failure - The Facts. Rijeka, InTech, 2012, DOI 10.5772/36832.

5 Murtagh FE, Marsh JE, Donohoe P, Ekbal NJ, Sheerin NS, Harris FE: Dialysis or not? A comparative survival study of patients over 75 years with chronic kidney disease stage 5. Nephrol Dial Transplant 2007;22:1955-1962. 


\section{Kidney \\ Blood Pressure Research}

6 Farrokhi F, Abedi N, Beyene J, Kurdyak P, Jassal SV: Association between depression and mortality in patients receiving long-term dialysis: a systematic review and metaanalysis. Am J Kidney Dis 2014;63:623635.

7 Teles F, de Azevedo VF, Miranda CT, Miranda MP, Teixeira MC, Elias RM: Depression in hemodialysis patients: the role of dialysis shift. Clinics 2014;69:198-202.

8 Greco A, Paroni G, Seripa D, Addante F, Dagostino MP, Aucella F: Frailty, disability and physical exercise in the aging process and in chronic kidney disease. Kidney Blood Press Res 2014;39:164-168.

9 Jiang W, Alexander J, Christopher E, Kuchibhatla M, Gaulden LH, Cuffe MS, Blazing MA, Davenport C, Califf RM, Krishnan RR, O’Connor CM: Relationship of depression to increased risk of mortality and rehospitalization in patients with congestive heart failure. Arch Intern Med 2001;161:1849-1856.

10 Gerogianni KS, Babatsikou PF: Psychological aspects in chronic renal failure. Health Sci J 2014;8:205-214.

11 Gerogianni KG, Babatsikou PF: Identification of stress in chronic haemodialysis. Health Sci J 2013;7:169176.

12 Feroze U, Martin D, Kalantar-Zadeh K, Kim JC, Reina-Patton A, Kopple JD: Anxiety and depression in maintenance dialysis patients: preliminary data of a cross-sectional study and brief literature review. J Ren Nutr 2012;22:207-210.

13 Wruk-Złotowska A: Lęki pacjentów dializowanych. Pielęgniarstwo Polskie 2006;2:158-166.

14 Bereza B: Źródła niepokoju pacjentów długotrwale hemodializowanych. Psychiatria w Praktyce Ogólnolekarskiej 2007;7:8-13.

15 Howden EJ, Coombes JS, Strand H, Douglas B, Campbell KL, Isbel NM: Exercise Training in CKD: Efficacy, Adherence, and Safety. Am J Kidney Dis 2015;65:583-591.

16 Gołębiowski T, Kusztal M, Weyde W, Dziubek W, Woźniewski M, Madziarska K, Krajewska M, Letachowicz K, Strempska B, Klinger M: A program of physical rehabilitation during hemodialysis sessions improves the fitness of dialysis patients. Kidney Blood Press Res 2012;35:290-296.

17 Kouidi E, Karagiannis V, Grekas D, Iakovides A, Kaprinis G, Tourkantonis A, Deligiannis A: Depression, heart rate variability, and exercise training in dialysis patients. Eur J Cardiovasc Prev Rehabil 2010;17:160-167.

18 Kouidi E, Albani M, Natsis K, Megalopoulos A, Gigis P, Guiba-Tziampiri O, Tourkantonis A, Deligiannis A: The effects of exercise training on muscle atrophy in haemodialysis patients. Nephrol Dial Transplant 1998;13:685-699.

19 Craft LL: Exercise and clinical depression: examining two psychological mechanisms. Psychol Sport Exerc 2005;6:151-171.

20 Dunn Al, Dishman RK: Exercise and the neurobiology of depression. Exerc Sport Sci Rev 1991;19:41-48.

21 Mitrou GI, Grigoriou SS, Konstantopoulou E, Theofilou P, Giannaki CD, Stefanidis I, Karatzaferi C, Sakkas GK: Exercise training and depression in ESRD: a review. Semin Dial 2013;26:604-613.

22 Aucella F, Gesuete A, Battaglia Y: A “nephrological” approach to physical activity. Kidney Blood Press Res 2014;39:189-196.

23 Storer TW, Casaburi R, Sawelson S, Kopple JD: Endurance exercise training during haemodialysis improves strength, power, fatigability and physical performance in maintenance haemodialysis patients. Nephrol Dial Transplant 2005;20:1429-1437.

24 Campbell MK, Elbourne DR, Altman DG: CONSORT group. CONSORT statement: extension to cluster randomised trials. BMJ 2004;328:702-708.

25 Murray DM, Varnell SP, Blitstein JL: Design and analysis of group-randomized trials: a review of recent methodological developments. Am J Public Health 2004;94:423-432.

26 Beck AT, Ward CH, Mendelson M, Mock J, Erbaugh J: An inventory for measuring depression. Arch Gen Psychiatry 1961;4:561-571.

27 Beck AT, Steer RA, Brown GK: Manual for the Beck Depression Inventory-II, San Antonio, TX, Psychological Corporation, 1996.

28 Spielberger CD, Gorsuch RL, Lushene RE: Manual for the State-Trait Anxiety Inventory, Palo Alto, California, Consulting Psychologists Press, 1970.

29 Wrześniewski K, Sosnowski T, Matusik D: State-Trait Anxiety Inventory: Polish adaptation of STAI, wyd. 4 rozszerzone Warszawa, Warszawa, Pracownia Testów Psychologicznych, 2011. 


\section{Kidney \\ Blood Pressure Research}

\section{Kidney Blood Press Res 2016;41:86-98}

DOI: $10.1159 / 000368548$

Published online: February 15, 2016

(C) 2016 S. Karger AG, Base

www.karger.com/kbr

30 Magnard J, Deschamps T, Cornu C, Paris A, Hristea D: Effects of a six-month intradialytic physical ACTIvity program and adequate NUTritional support on protein-energy wasting, physical functioning and quality of life in chronic hemodialysis patients: ACTINUT study protocol for a randomised controlled trial. BMC Nephrol 2013;14:259-267.

31 Sapilak BJ, Steciwko A: Depresja i zaburzenia lękowe występujące w trakcie leczenia nerkozastępczego - jak postępować z pacjentem (na podstawie 3-letnich badań własnych). Polska Medycyna Rodzinna 2004;6:1345-1346.

32 Knapen J, Vancampfort D, Moriën Y and Marchal Y: Exercise therapy improves both mental and physical health in patients with major depression. Disabil Rehabil 2014;24:1-6.

33 Szczepańska-Gieracha J, Morka J, Kowalska J, Kustrzycki W, Rymaszewska J: The role of depressive and anxiety symptoms in the evaluation of cardiac rehabilitation efficacy after CABG surgery. Eur J Cardiothorac Surg 2012;42:e108-e114.

34 Nowicki M, Jagodzińska M, Murlikiewicz K, Niewodniczy M: Aktywność fizyczna chorych przewlekle dializowanych - porównanie skuteczności różnych metod jej zwiększania. Postępy Nauk Medycznych 2010;10:799-804.

35 Ouzouni S, Kouidi E, Sioulis A, Grekas D, Deligiannis A: Effects of intradialytic exercise training on healthrelated quality of life indices in haemodialysis patients. Clin Rehabil 2009;23:53-63.

36 Aucella F, Valente GL, Catizone L: The role of physical activity in the CKD setting. Kidney Blood Press Res 2014;39:97-106.

37 Penninx BWJH, Rejeski WJ, Pandya J, Miller ME, Di Bari M, Applegate WB, Pahor M: Exercise and depressive symptoms: a comparison of aerobic and resistance exercise effects on emotional and physical function in older persons with high and low depressive symptomatology. J Gerontol B Psychol Sci Soc 2002;57B:124132.

38 Frazer CJ, Christensen H, Griffiths KM: Effectiveness of treatments for depression in older people. Med J Aust 2005;182:627-632.

39 Brenes GA, Williamson JD, Messier SP, Rejeski WJ, Pahor M, Ip E, Penninx BW: Treatment of minor depression in older adults: a pilot study comparing sertraline and exercise. Aging Ment Health 2007;11:6168.

40 Simon W: Motivational factors and the psychotherapeutic change. Polish Psychiatry 2008;42:335-352. 